\title{
SPECULATIVE AND CRITICAL DESIGN — FEATURES, METHODS, AND PRACTICES
}

\author{
Johannessen, Leon Karlsen; Keitsch, Martina Maria; Pettersen, Ida Nilstad \\ Department of Design, Faculty of Architecture and Design, NTNU, Norwegian University of Science \\ and Technology, Norway
}

\begin{abstract}
Speculative and Critical Design (SCD) confronts traditional design practice. Instead of reproducing and reinforcing contemporary perceptions of products and services, SCD seeks to change them, with the goal to spur a public debate e.g. on what is a preferable societal development. SCD methods comprise among others speculative narratives and design of critical objects. However, the theoretical fundament of SCD is feeble, and concepts and methods are upheld of mere examples.

The article aims to present the features, methods, and practice of SCD, and locate it in the design field. Following the introduction, section 2 presents features and SCD methods and practices. Section 3 links SCD to traditional design and identifies benefits and challenges relating to its role as a supplement to today's design practice. The final section suggests topics for further SCD research.

The article benefits designers in search for alternatives to commercially oriented design approaches. Findings indicate that SCD can contribute to creating new societal roles for designers, foster innovation in the relationship between designers and users, and encourage creativity through imaginative aesthetics.
\end{abstract}

Keywords: Speculative and Critical design, Discursive design, Design theory, Design methodology, Ethics

\section{Contact:}

Johannessen, Leon Karlsen

Norwegian University of Science and Technology

Department of Design, Faculty of Architecture and Design

Norway

leon@plysjbyen.net

Cite this article: Johannessen, L.K., Keitsch, M.M., Pettersen, I.N. (2019) 'Speculative and Critical Design - Features, Methods, and Practices', in Proceedings of the 22nd International Conference on Engineering Design (ICED19), Delft, The Netherlands, 5-8 August 2019. DOI:10.1017/dsi.2019.168 


\section{INTRODUCTION}

Speculative and Critical Design (SCD) emphasize ethical and societal features of design practice. One aim is to reveal underlying agendas, and explore alternative values, forms, and representations (Bardzell \& Bardzell, 2013). This excavation comprises at least three categories of change:

1. Political and social change: During the last four decades, design practice has been significantly reframed (Sanders \& Stappers, 2008). To incorporate novel approaches, design practice needs restructuring: When designers widen their scope towards ethical, political or social issues, selfreflection and a critical attitude towards why we design is required. One can for example ask if restructuring is possible if designers invariably must adhere to the norms of commercial industry.

2. Product value and user experience change: The utility value of products and services is increasingly supplemented by emphasis on semantic and social values. Consequently, when interpretations of products and services change, the design process must be rethought (Marenko, 2015). Criticism of industry to force designers to create persuasive, habit-forming even addictive products to get the user 'hooked' (Eyal, 2014) is not new (Hestad \& Keitsch, 2009). However, it gets a renewed importance in SCD e.g. as non-instrumental designer-user interactions and contextual dialogue about needs and desires.

3) Aesthetics: The 1960s experienced a significant influx of science fiction elements in popular culture (Klus, 2012). Many ideas conceived in sci-fi are today real products. Inspired by visions of space travel and radical, futuristic utopias, engineers and designers developed technology that drastically transformed society. For example, Stanley Kubrick's '2001: A Space Odyssey' exposed cinemagoers to the ideas of tablet computers, Skype-like video telecommunication, computers controlled with conversational interfaces like Apple's 'Siri' etc. SCD employs the imaginative creativity of Sci-Fi for future innovation e.g. as social dreaming approach.

In summary, Speculative and Critical Design are normative concepts that emphasize wider social implications of design. Instead of reproducing and reinforcing ubiquitous perceptions of products and services, SCD concepts confront commercial and traditional design practices with new ideas (Mitrović, 2015). Further, SCD strives to encourage designer-user dialogue and public debate about preferable societal development, among others with help of creative, narrative and aesthetic methods. Boundaries between SD and CD are fluid and the authors have chosen to sometimes summarize concepts under the common term SCD. The following section presents an appraisal of SCD literature (Dunne, 2006). Literature discussed was retrieved through a keyword search on 'speculative design' and 'critical design', 'design fiction', 'design criticism', 'discursive design'. Seminal works, such as 'Design Noir' (Dunne \& Raby, 2001) and 'Speculative Everything' (Dunne \& Raby, 2013), pivotal research articles relating to Critical Design and Speculative Design, respectively (Mitrović, 2015) and grey literature such as online documents and -presentations are considered.

\section{FEATURES, METHODS AND PRACTICE OF SCD}

The primary goals of this section are to present main features, methods and practices of SCD, and to locate this historically and systematically in the design field. SCD canon texts present exhaustive, categorical definitions of foundational terms, which are to some extent intentionally contradictory, as Dunne and Raby point out: "Speculative everything is an intentionally eclectic and idiosyncratic journey through an emerging cultural landscape of ideas, ideals, and approaches. We hope designers interested in doing more than making technology easy to use, sexy and consumable will find this book enjoyable, stimulating and inspiring." (Dunne \& Raby, 2013, p. vi) 


\subsection{SCD features and background}

In their book 'Speculative Everything', Dunne and Raby elaborate on the B part of their 'A/B manifesto’ (Table 1) (Dunne \& Raby, 2013).

Table 1: Excerpt from A/B manifesto (Dunne \& Raby, 2013, p. vii).

\begin{tabular}{|l|l|}
\hline A & B \\
\hline Affirmative & Critical \\
\hline Problem solving & Problem finding \\
\hline Provides answers & Asks questions \\
\hline For how the world is & For how the world could be \\
\hline Makes us buy & Makes us think \\
\hline
\end{tabular}

The manifesto comprises two connected categories, where each element has a direct counterpart in the other. $A$ represents what Speculative design (SD) is not, whereas $B$ represents what it is. Dunne and Raby stress that $B$ is not a replacement for $A$-rather SD complements traditional design. They acknowledge that most design work falls into the ' $A$ '-category, and hold that most future design work should continue to do so. However, in their view, there should exist another type of design practice, the 'B'-part of the list, to widen the horizon of design and avoid that the world develops in a tapering direction. For designers to be critical, inquisitive, and apt at problem finding, Dunne and Raby introduce the act of speculation (Dunne \& Raby, 2013): an activity where conjecture is as good as knowledge, where futuristic and alternative scenarios convey ideas, and where the goal is to emphasize implications of 'mindless' decisions for humanity.

\subsubsection{Terms and etymology}

The term 'Critical Design' was coined by Anthony Dunne and Fiona Raby, and first used in 'Hertzian Tales' as part of Dunne's 1999 dissertation (Dunne, 2006). Later, Dunne and Raby elaborated on the term in their 2001 book 'Design Noir: The Secret Life of Electronic Objects', where they write: "Instead of thinking about appearance, user-friendliness or corporate identity, industrial designers could develop design proposals that challenge conventional values" (Dunne \& Raby, 2001, p. 59).

Etymologically, the word critic comes from Greek 'kritikos' 'able to make judgments,' and 'krinein' 'to separate, decide', ${ }^{1}$ and is often connoted with 'finding faults' and 'censoring'. Critical thinking that questions the practice of design is a major component of Speculative Design (Mitrović, 2015). Yet, for example Dunne and Raby do not understand critique as something negative: It can be a gentle refusal of society's conditions, a critique of norms; a shift towards why we design instead of how and what we design, a critique of design practice; a practice where the needs of the industry are not taken for granted, a critique of capitalist culture; or where critical questions can and will be raised, a critique of cursory attitude. The goal of CD is to affect how the social world develops. By provoking the public to think critically about norms and values, $\mathrm{CD}$ practice strives to encourage public debate.

\subsubsection{Conjunction with postmodern discourse theory}

In $\mathrm{CD}$ practice, the designer aims to encourage critical reflection and to provoke new ways of thinking, by raising carefully crafted questions through the design of what Dunne and Raby call props (Dunne \& Raby, 2001). SD strives to foster social dreaming and discussion on what the future should be (Mitrović, 2015). A main communicative feature in SD and CD can be connoted by the term 'discourse', which e.g. implies the goal to raise questions and encourage debate, not to provide answers or create solutions. The term 'discourse' refers to postmodernist Michel Foucault (McHoul \& Grace, 1997). Foucault discusses the relation between discourse, power and knowledge. A discourse displays ways of organizing and producing knowledge, while language is a crucial mean of exerting power, for example by influencing what is true, acceptable and practical. Discourse power is executed by controlling communication, for example defining who is ill or healthy, what is legal or prohibited, what is a useful or inadequate product, etc.

The most powerful discourse defines what norms apply in society. Both SD and CD claim that encouraging social debate enables people to engage with the ideas that are the foundation of divergent

\footnotetext{
${ }^{1}$ Etymology dictionary: https://www.etymonline.com/word/critic, accessed 22 July 2018
} 
norms. SD thereby exceeds CD methodologically by applying narrative qualities of film and novels, to make the critical questions accessible to a broader audience. Although CD imagines alternative social, cultural, technical and economic values of society, and to a certain extent exercises speculation, its scope is somewhat limited by Dunne and Raby's focus on the lack of aesthetic qualities in the interactions between humans and electronic objects. With SD, they propose a bigger scope and highlight the opportunities of working with society-scale issues like alternatives to democracy or capitalism (Dunne \& Raby, 2013).

Scepticism towards consumer culture is a key feature of SCD. Dunne and Raby emphasize critical thinking (Dunne \& Raby, 2013), however, in their view, "all good design is critical", and every designer should question assumptions that are given.

\subsubsection{The genealogy of SCD}

Proposing a critical attitude of the designer has roots in design history. The ideas of William Morris, and the mid-19th century Arts and Crafts movement in Britain, were based on values challenging those of the contemporary industry (Raizman \& King, 2003). Morris's ethos refused capitalist and consumerist ideas, an ideal that later became an inspiration for the Weimar schools of craft and after that the Bauhaus. Tharp and Tharp describe anti-design and radical design, two avant-garde postmodernist movements of the 1960s and 1970s, as predecessors of SCD (Tharp \& Tharp, 2015). In the same period, engineering and traditional design became increasingly close-knit and market-driven (Keitsch, 2010). The anti-design and radical design movements were responses to this development. Mitrović makes a similar historical connection; the designer's role is more like an artist's than an engineer's (Mitrović, 2015). Dunne and Raby acknowledge this link, but crave a bigger role for CD than the reactionary movements of the 1960s and 1970s: "Critical Design must avoid the pitfalls of the 1970s by developing strategies that link it back to everyday life and fully engage the viewer" (Dunne \& Raby, 2001, p. 59). The narrative, 'accessible' qualities of SCD is a response to this craving (Mitrović, 2015). Inspired by the engaging, imaginary worlds of literature and film - and in particular the worlds seen in science fiction - SCD started using speculative narratives to bring disruptive and critical ideas concerning society into the discourse. For instance, Dunne and Raby refer to Margaret Atwood's dystopian science fiction novel 'Onyx and Crake' as the gold standard for speculative work (Dunne \& Raby, 2013). The inspiration from science fiction seems closely related to a fascination with social dreaming.

Dunne argues that social dreaming was more common before (Dunne \& Raby, 2013). Compared to contemporary sci-fi, 1970s sci-fi was more pioneering, and this, in tandem with the rapid technological advances of the period, fostered widespread social dreaming throughout society. While children of the 1970s dreamt about space travel (Mitrović, 2015), present-day children dream of Instagram likes and are anxious about losing 'Snapchat streaks' (Anon, 2017). By bringing narrative qualities of the science fiction into the world of design, and by envisioning utopian, as well as dystopian scenarios, Dunne and Raby attempt to re-ignite such social dreaming. Their hope is that societal issues can be brought into public debate by 'expressing the unthinkable' through the language of design. In the same vein are the links to Victor Papanek's works in the 1970s (Marenko, 2015): Papanek famously named traditional design among the most harmful and phony professions, because of its links to capitalist culture-a culture where, according to Papanek, people are lured to borrow money to buy things they don't need, to impress people that don't care. Papanek envisioned a greater role for design, integral to the world's development in environmental and social terms (Raizman \& King, 2003). Papanek was both utopian and dystopian: On one hand, he imagined worlds where idealistic organizations directed design, so that efficient use of resources and a broader public and social interest always was the basis for development. On the other hand, he envisioned the environmental hazards that unlimited production and consumption would cause. According to Auger (Mitrović, 2015), SCD acts as a corrective to design as taught in most design schools-without a critical and philosophical foundation - which propagates to the naïve way design is practiced by many designers. If designers do not consider the implications of their work, they do so because of fallacies learnt in design schools: that all design is good, that design solves problems, and that design makes people's lives better. SCD suggests that design can do all those things, but not if practiced 'mindlessly', solely to reach commercial goals. 


\subsection{SCD methods and practice}

\subsubsection{The SCD position}

Methodologically, Dunne and Raby suggest no unique, freestanding methodology to use for conducting SCD, which probably is why they rely on examples and point to related fields to define what SCD practice is (Bardzell \& Bardzell, 2013). In their view, SCD is not a methodology, but rather a position the designer takes on. In this position, the SCD designer draws from the 'designer's toolkit' and adapts whatever method is suitable in a particular situation, to spur debate (Mitrović, 2015). Methodologically, SCD makes use of speculations and conjectures, rather than of facts and information, as a basis for design (Dunne \& Raby, 2013). SCD results do not need to be fruitful in a commercial context. Instead, it should strive to be imaginative, and foster social dreaming on how the world might develop, as well as how the world might have been if prior development had been different.

Normative SCD principles are reflected in practice as well, for example linked to the activity of making criticism of societal development available to a greater audience, and to spur debate about what is a preferable future (Auger, 2013). SCD also asks how a preferable future differs from the probable future. The purpose of these activities is to express ideas that encourage discourse on how the social world is today and how it should develop, and to question why we design at all. Regarding the designers attitude critical thinking must be the fundament for design practice, in principle a designer should question everything (Mitrović, 2015). In particular, designers must cultivate a critical attitude towards the commercial industry, technology, and the norms given by society. If designers 'mindlessly' innovate based on available technology, the commercial needs of the industry, and not question development, it may cause wider, initially concealed, and possibly unwanted social implications.

\subsubsection{Step 1- Define a context for debate}

SCD practice revolves around a topic - the context an SCD designer wants to put into social debate (Dunne \& Raby, 2013). The first step is to define this context. Typical topics are contemporary, ethical issues created by commercial industry, emerging technology, or social norms. 'How society is dependent on technology' and 'how a 'big data'-driven economy affects social life' are examples of potential topics.

\subsubsection{Step 2 - Ideate, find problems, and create a scenario}

The next step is to ideate to find problems to explore a topic. SCD practice uses series of 'what if?'questions (Dunne \& Raby, 2013). For example 'how might this topic develop in the future', 'what would the issue look like today if some prior development had been radically different', etc. Another way to explore a topic is through questions that lead to 'reductio ad absurdum' arguments, e.g. 'how might a continuation of development lead to a ridiculous, absurd, or impractical situation?' To elaborate on these problems further, the SCD designer draws from the 'designer's toolkit' and adapts whatever method suitable (Mitrović, 2015). The most effective problems form the basis of a scenario. SCD makes use of two types of scenarios: The design of alternative presents and the speculation about possible futures (Mitrović, 2015). The first scenario is effective to analyze society in its current form, and the latter to analyze the direction of development (see Figure 1 below). To strengthen the scenarios and support 'suspension of disbelief', several questions are considered such as 'when is the problem positioned', 'which rules apply in the scenario', 'would the scenario be more effective as a utopia or a dystopia', and 'what perceptual bridge exists between the present and the scenario'? 


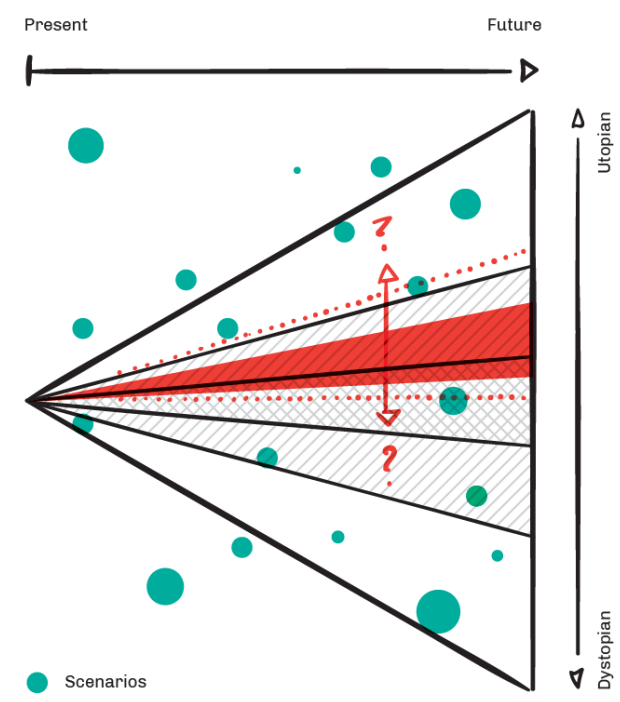

Figure 1: PPPP model with scenarios mapped over the cones. The scenarios represent alternative presents or speculative futures varying between utopian or dystopian. Adapted from Mitrović (Mitrović, 2015, p. 19).

\subsubsection{Step 3-Materialise the scenario to provoke an audience}

To provoke its intended audience to engage with and debate the topic of the scenario, the last step of the process is to materialize the scenario as either narratives, objects, or a combination of both (Auger, 2013). Objects, or props, can be either physical or digital, and, as prop suggest, an object may be fake and non-functional, as long as it appears to be a real representation of a concept (Dunne \& Raby, 2013). The prop could for instance, be a product catalog presenting imaginary products, a map of a fictional area, or a website for a bogus event. However, to achieve realness, the prop must have a sufficient level of detail. It is up to the designer to decide which level of detail and functionality is appropriate; some scenarios might need props with a high level of detail to be provoking, while other scenarios may benefit from the imaginative qualities of simple sketches.

The narratives adopt aesthetic and story-telling techniques found in film, TV series, and literature to communicate the ostensible problems to the audience in a convincing and engaging way (Mitrović, 2015). For example, they may take the form of documentary film, where a phenomenon in a made-up scenario is presented with the credibility and authority of the documentary genre. Commercial videos for fake Kickstarter projects, video blogs that 'unbox' imaginary products, or regular written novels or comics where the stage is set in a utopian or dystopian world are other examples of possible fictional narratives. Often the fictional narratives make use of the props, in the same way that is common in conventional films, to facilitate suspension of disbelief.

The SCD designer uses whatever method applicable to construct the narrative, and iterates until it is provocative enough to make the audience engage with the intended topic. Various tools are considered to make the audience engage on an emotional, psychological, and intellectual level (Mitrović, 2015). Whereas traditional design often strives to make messages as clear as possible to enable users to think less, the SCD practice attempts to do the opposite. In SCD discursive practice, it is important to ask questions without dictating the audience's perception of an answer or a solution (Tharp \& Tharp, 2013). Therefore, to enable the audience to entertain personal interpretations, SCD scenarios are often open-ended, unclear, and complicated, and strive to provoke using dark humour and satire.

\section{SCD AND MAINSTREAM DESIGN}

The term 'mainstream design' relates in SCD to design driven by a commercial impetus. Even if main authors are rather vague in their attribution of mainstream design, it plays the role of a counterpart to SCD. Mainstream design comprises 'commercial design', 'industrial design', 'affirmative' and 'traditional design' (Dunne \& Raby, 2001; Dunne \& Raby, 2013; Mitrović, 2015). SCD authors firstly emphasize the commercial aspect - the primary purpose of design is to make money for the industry. Secondly, the purpose of mainstream design is to solve problems for industry, address the client's needs, and conform exiting cultural, economic and technical expectations of society. Mainstream 
design practice can for instance, be user-centred, in the sense that designers strive to make products user-friendly. At the same time, they argue that these types of considerations are limited: If design practice is an instrument of the commercial industry, a successful outcome of design always represents expectations of a client, while use or society needs remain subordinate (Tharp \& Tharp, 2013). Comparing mainstream design and SCD the following features can be illustrated in Table 2 (by the authors).

Table 2: Comparison of mainstream design and SCD

\begin{tabular}{|l|l|l|}
\hline & Traditional design & SCD \\
\hline Attitude & Normative & Critical \\
\hline Foundation & Information & Speculation \\
\hline Mindset & $\begin{array}{l}\text { Pragmatic } \\
\text { Productive }\end{array}$ & $\begin{array}{l}\text { Idealistic } \\
\text { Dreaming }\end{array}$ \\
\hline Purpose & $\begin{array}{l}\text { Commercial } \\
\text { Satisfy industry's need } \\
\text { to make money }\end{array}$ & $\begin{array}{l}\text { Discursive } \\
\text { Spur debate on the } \\
\text { development of society }\end{array}$ \\
\hline Goal & $\begin{array}{l}\text { Develop solutions } \\
\text { Provide answers by } \\
\text { solving problems }\end{array}$ & $\begin{array}{l}\text { Explore ideas } \\
\text { Find problems by } \\
\text { asking questions }\end{array}$ \\
\hline Intent & $\begin{array}{l}\text { Serve a user } \\
\text { In seriousness } \\
\text { provide clarity }\end{array}$ & $\begin{array}{l}\text { Provoke an audience } \\
\text { Use ambiguity to } \\
\text { make satire }\end{array}$ \\
\hline
\end{tabular}

The SCD view on mainstream design as short-sighted and commercially oriented is ontologically but not epistemologically justifiable. In the following, two approaches that partly overlap with SCD are discussed.

In a comprehensive model, Sanders and Stappers illustrate that the 'conventional' design process includes activities that originally were not part of the product design process (Figure 2) (Sanders \& Stappers, 2014), such as pre-design research to understand needs of several stakeholders, as well as 'post-design'-activities, to evaluate the result. Sanders and Stappers's model also includes different types of intent for design: Serving, engaging, or provoking, different design areas, different timeframes and contrasting mind-sets of user involvement. From their perspective, divergent and critical thinking is a prerequisite for the design process and its results.

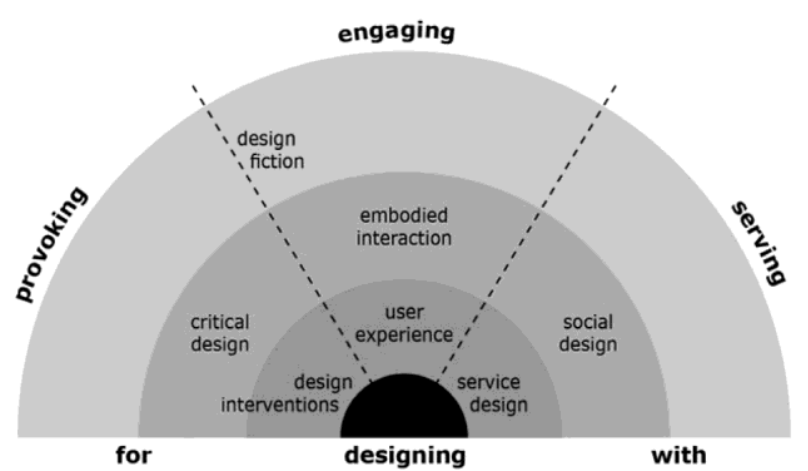

Figure 2: The inner circle represents design for the world "as itis", the middle circle represents design for a near future, while the outer circle represents a speculative future (Sanders \& Stappers, 2014, p. 13).

Tharp and Tharp describe Discursive Design as the creation of products "whose primary purpose is to communicate ideas-they encourage discourse" (Tharp \& Tharp, 2013). Social debate is the fundamental goal and desired outcome of Discursive Design; making products that facilitate this debate is the primary activity of the designer. The term product is used in its broadest sense; it can refer to anything from a service concept sketch to a physical prototype. A product is any artefact serving a communicative purpose. Tharp and Tharp situate discursive products within a twodimensional model, shown in Figure 3 below (Tharp \& Tharp, 2013). On the first axis, they place the 
intended audience: either an internal audience, an esoteric group with specialized knowledge of a specific domain; or an external audience - the public. The second axis concerns the role of the product and the role of the designer. For a terminal discursive product, the job of the designer ends when the product is presented, the designer relies on the product itself to convey ideas that spark debate among its audience. On the contrary, an instrumental product serves as a provocative tool to stimulate discussion between the audience and the designer - either where the debate itself is part of a larger design research process, or where the product can steer the discussion in a given direction.

\section{Terminal}

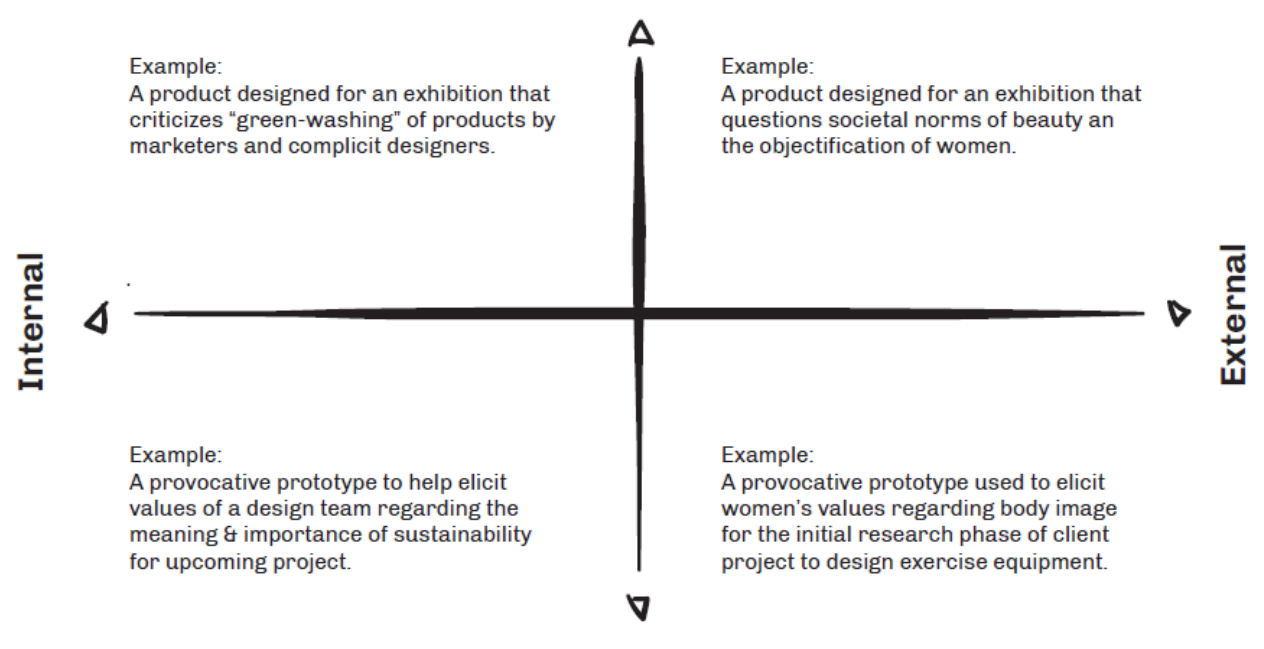

Instrumental

Figure 3: Types of discursive products (Tharp \& Tharp, 2013, p. 409).

\section{CONCLUSION}

The ongoing scope shift in the design field towards society-scale issues and questions such as whether designers are apt as contributors to social transformation requires ways of alternative thinking. Additionally, in the last decades, new working areas for designers such as health- and public service design have emerged, that require reflection on e.g. the commercial purpose of design, the various roles a designer plays in society and her/his relation to users and stakeholders.

SCD is presented as an alternative to traditional design practice and Dunne and Raby see it as morally high-grounded and imply that the SCD designer should facilitate the masses to find a 'preferable' development for society. This assertion come with certain challenges. For example, the idea that the designer may feel that he or she knows what is best for people evokes a critique of elitism. Also, SCD based designs are not necessarily more sustainable or better for society per se.

In summary, there are several possible topics for further SCD research and practice. First, in the contemporary design field, there exist multiple future-oriented design methodologies. Vision in Design (ViP) (Hekkert et al., 2011) is one of them. In the emerging field of transition design, Lockton and Candy (2019) introduce several other perspectives or 'lenses' potentially useful to the development of future visions. However, many questions remain: How does this compare to SCD? What are the similarities and differences, and are there parts of other future-oriented approaches that can be incorporated into SCD - or the other way around? Further, within transition design, where the creation of visions for transition to sustainable futures is central, new mindsets and postures are considered an important part of developing alternative ways of designing, but so are new theories of change (Irwin, 2015). How can such theories shape and contribute to SCD based work, and vice versa? Second, critique of norms is a central component in SCD. However, SCD seemingly has many norms of its own, and most topics revolve around the 'domestication of technology' and can be classified as 'white man's' problems (Pierce, 2015). Another emerging design research topic is how SCD can be applied to social justice and larger-scale global-South issues. Finally, are there other ways to codify and present SCD practice? What can be done to make SCD accessible to a wider range of designers?

Besides the need to respond to these questions, SCD represents alternative ways of thinking and contributing to launching ideas, of which Foucault was saying: "There are more ideas on earth than 
intellectuals imagine. In addition, these ideas are more active, stronger, more resistant, more passionate than politicians think. We have to be there at the birth of ideas, the bursting outward of their force: not in books expressing them, but in events manifesting this force, in struggles carried on around ideas, for or against them. Ideas do not rule the world. But it is because the world has ideas ... that it is not passively ruled by those who are its leaders or those who would like to teach, once and for all, what we must think." (Foucault, M., as cited in Eribon, D., 1991)

\section{REFERENCES}

Anon (2017), «Snapstreak» gjør deg til en av de kule. Nå er jeg sliten. [Internet] Available at: http://www.aftenposten.no/meninger/sid/Snapstreak-gjor-deg-til-en-av-de-kule-Na-er-jeg-sliten615942b.html [Accessed 28 February 2017].

Auger, J. (2013), "Speculative design: crafting the speculation". Digital Creativity, Vol. 24, pp. 11-35.

Bardzell, J. and Bardzell, S. (2013), "What is critical about critical design?". Proceedings of the SIGCHI conference on human factors in computing systems, pp. 3297-3306.

Dunne, A. (2006), Hertzian Tales: Electronic Products, Aesthetic Experience, and Critical Design. 2006 edition red. The MIT Press, Cambridge.

Dunne, A. and Raby, F. (2001), Design Noir: The Secret Life of Electronic Objects. Springer Science \& Business Media, N/A.

Dunne, A. and Raby, F. (2013), Speculative Everything: Design, Fiction, and Social Dreaming. MIT Press, Cambridge (Massachusetts).

Eyal, N. (2014), Hooked: How to Build Habit-Forming Products. Penguin, London.

Foucault, M., as cited in Eribon, D. (1991), Michel Foucault. 1st red.: Harvard University Press.

Hekkert, P., van Dijk, M. and Lloyd, P. (2011), Vision in Product Design - handbook for innovators. BIS publishers, Amsterdam.

Hestad, M. and Keitsch, M. (2009), "Not always a victim! On seeing users as active consumers". International Journal of Product Development (IJPD), Vol. 9 No. 4, pp. 396-405.

Irwin, T. (2015), "Transition Design: A Proposal for a New Area of Design Practice, Study, and Research". Design and Culture, Vol. 7 No. 2, pp. 229-246.

Keitsch, M.M. (2010), “A postmodernist approach to product semantics". Design Semiotics in Use, pp. 24-39.

Klus, H. (2012), Why Society Needs Science Fiction. [Internett] Available at: http://www.thestargarden.co.uk/Why-society-needs-science-fiction.html [Accessed 13 March 2017].

Lockton, D. and Candy, S. (2019), "A Vocabulary for Visions in Designing for Transitions". Cuaderno, Vol. 73, pp. $27-49$.

Marenko, B. (2015), Deleuze and Design. Edinburgh University Press, Edinburgh.

McHoul, A. and Grace, W. (1997), A Foucault primer: Discourse, power, and the subject. NYU Press, New York.

Mitrović, I. (2015), An Introduction to Speculative Design Practice. Split: Department for Visual Communications Design, Arts Academy, University of Split.

Pierce, J.e.a. (2015), Expanding and Refining Design and Criticality in HCI. Proceedings of the 33rd Annual ACM Conference on Human Factors in Computing Systems, pp. 2083-2092.

Raizman, D.S. and King, L.P. (2003), History Of Modern Design. s.l.:Prentice Hall PTR.

Sanders, E.B.-N. and Stappers, P.J. (2008), "Co-creation and the new landscapes of design". CoDesign, Vol. 4 No. 1 , pp. $5-18$.

Sanders, E.B.-N. and Stappers, P.J. (2014), "Probes, toolkits and prototypes: three approaches to making in codesigning". CoDesign, Vol. 10, pp. 5-14.

Tharp, B.M. and Tharp, S.M. (2013), "Discursive design basics: Mode and audience". Nordes, Nordic design research, Vol. 5, pp. 406-409.

Tharp, B.M. and Tharp, S.M. (2015), What is Discursive Design. [Internet] Available at: http://www.core77.com/posts/41991/What-is-Discursive-Design [Accessed 3 March 2017]. 
